\title{
NRAS NM_002524.4:C.182A>G
}

National Cancer Institute

\section{Source}

National Cancer Institute. NRAS NM 002524.4:C.182A>G. NCI Thesaurus. Code C98457.

A nucleotide substitution at position 182 of the coding sequence of the NRAS gene

where adenine has been mutated to guanine. 